\title{
A APREENSÃO ORIGINÁRIA DA VIVÊNCIA DA CONSCIÊNCIA
}

\author{
THE ORIGINAL APPREHENSION OF THE EXPERIENCE OF CONSCIOUSNESS
}

\section{LA APREHENSIÓN ORIGINAL DE LA EXPERIENCIA DE LA CONSCIENCIA}

\author{
Caio César Costa Santos \\ E-mail: cesarinmind@gmail.com \\ Universidade Federal de Sergipe (UFS)
}

\begin{abstract}
RESUMO
Neste artigo, pretendo esboçar o itinerário do fundamento fenomenológico em torno da apreensão originária da vivência da consciência. Pretendo ainda, com alguns exemplos do próprio Husserl, esclarecer alguns conceitos da fenomenologia como "vivido", "vivido de percepção", "vivido de consciência", "vivência", "mundo da vida", etc. O nosso objetivo é tentar delinear como Husserl via a "consciência", alertando, aos leitores leigos, sobre a crítica ardorosa contra qualquer posição cognitivista que via a consciência como meramente uma "coisa", um dado empírico verificável. Husserl, ao contrário, vê a "consciência" como um "fenômeno", ou seja, como um dado originário da experiência. Veremos, nas linhas subsequentes, que o conceito de "consciência" husserliano advém, sobretudo, do "vivenciamento" da experiência e das vivências brotadas desta relação. Concluo dizendo que a vivência da consciência segundo um esquema husserliano só pode ser captada através do experienciamento da vida psíquica mais do que da vida natural.
\end{abstract}

PALAVRAS-CHAVE: Apreensão originária. Vivência. Consciência.

\section{ABSTRACT}

In this paper, I intend to outline the itinerary of the phenomenological foundation around the original apprehension of the experience of consciousness. I also intend, with some examples from Husserl himself, to clarify some concepts of phenomenology such as "lived", "lived from perception", "lived from consciousness", "living", "world of life", etc. Our aim is to try to outline how Husserl saw "conscience", alerting lay readers to the ardent criticism against any cognitive position that viewed conscience as merely a "thing", a verifiable empirical fact. Husserl, on the contrary, sees "consciousness" as a "phenomenon", that is, as a data originating from experience. We will see, in the subsequent lines, that the concept of Husserlian "conscience" comes, above all, from the "living" of the experience and the experiences that sprouted from this relationship. I conclude by saying that the experience of consciousness according to a Husserlian scheme can only be captured through experiencing psychic life more than natural life.

KEYWORDS: Original apprehension. Experience. Consciousness.

\section{RESUMEN}

En este artículo pretendo esbozar el itinerario del fundamento fenomenológico en torno a la aprehensión original de la experiencia de la conciencia. También pretendo, con algunos ejemplos del propio Husserl, aclarar algunos conceptos de la fenomenología como "vivido", "vivido de la percepción", "vivido de la conciencia", "vivir", "mundo de la vida", etc. Nuestro objetivo es tratar de delinear cómo Husserl veía la "conciencia", alertando a los lectores legos de la ardiente crítica contra cualquier posición cognitiva que viera la conciencia como una mera "cosa", un hecho empírico verificable. Husserl, por el contrario, ve la "conciencia" como un "fenómeno", es decir, como un dato procedente de la experiencia. Veremos, en las líneas siguientes, que el concepto de "conciencia" husserliana proviene, sobre todo, del "vivir" de la experiencia y de las vivencias que brotaron de esta relación. Concluyo diciendo que la experiencia de la conciencia de acuerdo con un esquema husserliano solo puede capturarse experimentando la vida psíquica más que la vida natural.

PALABRAS CLAVE: Aprehensión original. Experiencia. Conciencia. 


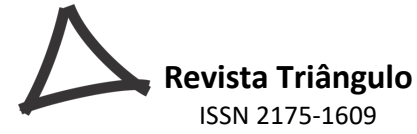

\section{INTRODUÇÃO}

A Fenomenologia é uma ciência que estuda os fenômenos originários da consciência. Edmund Husserl (1859-1938) foi o fundador desta "escola". O ponto crítico do pensamento de Husserl era o estudo das "manifestações" da consciência quando relacionada com o mundo natural. Tudo começa no ato intencional provocando uma percepção e, logo em seguida, uma reflexão do objeto percebido. Neste artigo, em particular, pretendo demonstrar o itinerário do fundamento fenomenológico em torno da apreensão originária da vivência da consciência.

Com base nas experiências concretas de Husserl com determinados objetos, tenho o objetivo de esclarecer alguns termos da fenomenologia como "vivido", "vivido de percepção", "vivido de consciência", "vivência", "mundo da vida", etc. O foco central está no esclarecimento destas terminologias que muitas vezes confundem o fenomenólogo inexperiente. Veremos que a atitude natural das coisas em relação ao seu vivenciamento não é a mesma coisa do contato experiencial com estas coisas, de modo a alertar para o fato de que a construção do campo psíquico das vivências tem sua relação com as dinâmicas interiorizadas no fluxo da experiência. Veremos ainda que o conceito de "consciência" husserliano não advém dos postulados psicologizantes, ao contrário, ele se reafirma na dissolução crítica de teorias que veem a consciência como meramente uma coisa. Lanço luz para este fato nos tópicos a seguir.

\section{A ORIENTAÇÃO NATURAL DAS COISAS E SUA RELATIVA APREENSÃo}

A Fenomenologia não é Fenomenologia sem a grandiosa figura de Edmund Husserl (1859-1938). A filosofia fenomenológica de Husserl surgiu no início do século XX como uma crítica às postulações do psicologismo. Neste contexto, a ciência tomada em seu substrato não passava de uma abordagem puramente empírica e experimental. Nesta época, a crítica que Husserl fazia às ciências do espírito era que estas fundamentavam suas teses em uma espécie de teoria psicológica, sem a introjeção do subjetivismo ou da subjetividade. Sendo que, tomada esta perspectiva, a visão da consciência não era analisada em seu sentido mais amplo, logo, os estudos psicológicos sobre a consciência limitavam-se à descrição sistêmica da mente como um composto orgânico em que o cientista era capaz apenas de contorná-lo em si mesmo, sem uma relação evidente com o mundo das coisas. Husserl, então, teve a sagacidade de enxergar além deste prisma, investigando não simplesmente o componente biológico da mente, mas as 


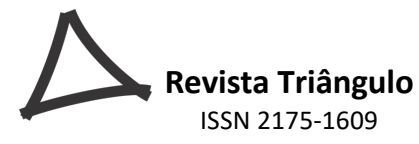

relações anímicas que a consciência tem com o mundo circundante. Vejam que Husserl toma, em seus estudos fenomenológicos, não a nomenclatura "mente", mas a "consciência", justamente porque podemos falar também de uma "consciência" das coisas e dos objetos.

Nesta perspectiva, a consciência está tão entrelaçada com o mundo que Husserl, em suas teses, chega a se questionar se o mundo natural inteiro pode ser separável, por princípio, do domínio da consciência. Digamos que toda a filosofia fenomenológica husserliana concentrase nesta questão: o mundo natural é inseparável do mundo da consciência e vice-versa? Diante de algumas leituras iniciais sobre esta questão em particular, podemos supor que a consciência só toma consciência de si mesma na interconexão com a organicidade do mundo natural. $\mathrm{O}$ mundo inteiro é bem maior, no entanto, a consciência, por ser fluída, pode abarcar este universo com uma só significação. O que queremos dizer com isto? Que a consciência é o ato reflexionante do mundo circundante. Na consciência, há um mundo. E não estamos se referindo apenas ao mundo particular da consciência, mas à totalidade do mundo em uma só consciência. A dinâmica ininterrupta do ato de pensar condensa as transformações incessantes do mundo circundante. Ao passo que a consciência funciona, ou seja, ao passo que eu tenho consciência de alguma coisa, eu logicamente preciso do mundo material para construir pontes com ele mesmo.

Partindo deste ponto, é incomensurável pensar que o mundo natural inteiro é inseparável do domínio da consciência. As coisas, os objetos, as relações espaço-temporais, a subjetividade, a memória, enfim, todos estes fenômenos estão contidos numa dada consciência que imagina, crê, pensa, constrói, reflete, percepciona, etc. Estimulado pela filosofia de seu antecessor, Descartes e mais precisamente, sobre o cogito cartesiano, Husserl observou que o "Penso, logo existo" era uma proposição verdadeira, no entanto, precisava-se fundamentá-la em um todo dinâmico que pudesse contornar toda a teoria de Descartes. E foi com este propósito que Husserl cria um método fenomenológico para "descrever" e, mais do que isto, para "tornar" concreto (no sentido literal da palavra) as conexões que existem entre o ser e a sua existência. Segundo Husserl (2006), os atos de consciência abrangem todos os vividos. "Vividos" aqui no sentido de que toda consciência perceptiva estar em conexão com uma coisa, objeto, artefato. O "vivido" seria o resultado do reflexo da experiência perceptiva da consciência humana ou animal. "Humana" e "animal" porque para todo ser organísmico vivo há logicamente uma experiência perceptiva, se bem que a grandiosidade do ato de perceber do homem não se compara à de outros seres vivos. 


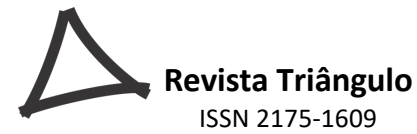

"Isso significa que não podemos submeter nossa percepção do mundo ao olhar filosófico sem deixarmos de nos unir a essa tese do mundo, a esse interesse pelo mundo que nos define" (MERLEAU-PONTY, 2018, p. 11). Toda nossa percepção está sujeita à designação do mundo. O mundo está dentro e fora, fora e dentro. Não há como impedir esta dissolução do mundo em nossas vidas. A percepção existe por conta da existência do mundo material. Nós tocamos o mundo e somos tocados por ele. Há uma completa simbiose neste ato recíproco. Esperamos "respostas" do mundo e ele nos convoca incessantemente à reflexão. Pela reflexão, construímos "pontes" com o mundo. Esta dada reflexão está antes e após a percepção concreta das coisas. Antes porque precisamos ter consciência do ato em si e depois porque precisamos categorizar o porquê estamos no momento percebendo. A consciência perceptiva é anímica por natureza porque é como se em cada coisa imersa no mundo existisse uma "luz interior" própria da construção ontológica da coisa. Há logicamente a luz de todas as luzes que é a luz do Sol, mas estamos tratando de uma "luz interior", ou seja, de uma animosidade ${ }^{1}$ inscrita nas coisas. Pela reflexão, então, podemos "ver" esta "luz" que brota do fundo da experiência, ás vezes opaco, das coisas.

Merleau-Ponty (2018, p. 11) diz: "não existe pensamento que abarque todo o nosso pensamento". O pensamento em si funciona alternadamente e em conjunto. Há uma dinâmica própria no ato de pensar. Podemos logicamente pensar acerca de uma coisa e, subitamente, vem um aglomerado de pensamentos sobre aquela mesma coisa e ainda outros sobre outra coisa totalmente distinta. É impossível que o pensamento abarque todo nosso pensamento porque estamos a todo instante pensando e refletindo, refletindo e pensando. Esta dinâmica do pensar é tão imediata que se passa desapercebida. Até "inconscientemente" estamos pensando. Durante o ato de pensar, um pensamento pode tornar-se o mais relevante por um dado instante, mas aí já vem outro e mais outro, sem podermos evidentemente controlá-los. Neste sentido, a nossa consciência funciona dentro de uma teia ininterrupta de pensamentos. Cada um está conectado em si e a outros. Por isso, podemos dizer, concordando com Merleau-Ponty, que não existe pensamento que condense todo o nosso pensamento. Mas, podemos dizer que há um mundo

\footnotetext{
${ }^{1} \mathrm{O}$ conceito de animosidade advém da Filosofia Antiga de Aristóteles. Devemos distinguir entre animosidade no sentido de ter anima e animosidade no sentido de ter rivalidade. Ter anima, seguindo uma tradição aristotélica, é o mesmo que dizer que um objeto $\mathrm{x}$ ou uma coisa x contém um germe de expressão singular constituído pela sua experiência singular no mundo. Enquanto que ter rivalidade é o contrário: significa dizer que o sujeito pensante não é anímico em suas decisões. Há, portanto, um conflito em sua expressão de dizer ou de experienciar originado do confronto ou do embate entre posições ideológicas divergentes. No entanto, o conceito de animosidade aqui quer dizer expressão, gesto, de uma coisa clara em que não há contradições.
} 


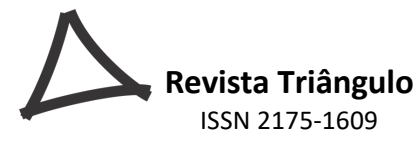

que contorne toda a nossa consciência, se bem que a nossa consciência pode se tornar muito "maior" do que o próprio mundo material porque existem coisas na "consciência" que não existem no mundo material.

De qualquer forma, a nossa consciência precisa do mundo natural para dar sentido ao próprio mundo e às coisas. Se não fosse a evidente existência do mundo natural, não tínhamos com que pensar a não ser em nós mesmos como uma ser totalmente fechado em si. Neste sentido, a "abertura" do mundo nos projeta para uma "abertura" da consciência. O próprio homem é um "vivido" e as coisas em nosso entorno são também "vividos"; tudo, então, está conectado com o "vivenciamento", ou seja, com a experiência perceptiva. Husserl (2006, p. 8485) esclarece: "na orientação natural não se podia ver mesmo outra coisa que o mundo natural. Enquanto não fora reconhecida a possibilidade de orientação fenomenológica e não fora desenvolvido o método de trazer à apreensão originária as objetividades que com ela surgem, o mundo tinha de permanecer um mundo desconhecido". Se não fosse justamente o ato reflexivo próprio do ser humano, nós iríamos cair em um mundo absoluto de meras objetividades. No entanto, nós estamos lançados à orientação natural das coisas, é com ela que nos projetamos ao mundo e construímos relações. Todos nós estamos voltados para o "mundo exterior" e é sem deixar a orientação e o movimento natural das coisas que, por uma reflexão psicológica, nos tornamos conscientes de nosso eu e de nossas vivências. Para cada vivência, há um vivido e para cada vivido há, por trás, um ato reflexivo.

A consciência se torna "consciência" ligeiramente pelo ato de reflexão. Husserl nos explica que o que nos torna seres viventes de experiência são os atos reflexionantes, as múltiplas formas de aparição do componente subjetivo. A subjetividade só se torna "subjetividade" pelo ato de reflexão. O mundo é dado a nós como algo objetivo, circunscrito e imediato. É, no entanto, a nossa consciência que faz todo o trabalho de apreensão originária das coisas pelo simples ato de reflexão. A cada vivência, o homem vai se conectando a um "nexo concreto" da essência própria da coisa, revelando assim, em seu substrato, o fluxo daquele vivido. É como se o homem "saísse" parcialmente de si e se introjetasse na essência do vivido daquela coisa. Nesta relação, Husserl explica que é como se existisse um nexo concreto entre dois vividos: o homem e a coisa. Dentro deste fluxo, é possível "captar" a essência própria da composição da coisa após o ato de perceber. Primeiro, o vivido é percebido e logo em seguida apreendido. Já no contato instântaneo da apreensão, o vivido passa a se "revelar" para o homem. Neste sentido, 
todo o percebido se dá evidentemente sobre um fundo da experiência. Vamos a um exemplo de Husserl (2006) para que se torne mais claro:

Tomemos alguns exemplos. Diante de mim, na penumbra, está esse papel branco. Eu o vejo, toco. Esse ver e tocar perceptivamente o papel, como vivido pleno e concreto do papel está aqui e, mesmo, do papel dado exatamente nessas qualidades, nessa relativa obscuridade, nessa determinidade imperfeita, aparecendo nessa orientação para mim - é uma cogitatio, um vivido de consciência. Esse papel, mesmo com suas propriedades objetivas, com sua extensão no espaço, situado objetivamente em relação à coisa espacial que chamo meu corpo, não é cogitatio, mas cogitatum, não vivido de percepção, mas percebido. Ora, um percebido mesmo pode muito bem ser um vivido de consciência; é evidente, porém, que algo assim como uma coisa material, por exemplo, esse papel dado no vivido de percepção, não é, por princípio, um vivido, mas um ser de uma espécie totalmente outra (HUSSERL, 2006, p. 87, grifos do autor).

É evidente que Husserl toma o cogito de Descartes para explicar e justificar a sua filosofia. Husserl percebera que o seu antecessor tinha mencionado a existência do cogito, mas, de fato, não o explicou de modo fenomenológico. Afinal, não era esta a pretensão de Descartes. Então, Husserl toma novamente este "conteúdo psíquico" para explicá-lo fenomenologicamente. Quando Husserl afirma estar na penumbra, em um ambiente com pouca ou quase nenhuma visibilidade, e percebe um papel branco, ele quer salientar que a "objetividade" do papel só passa a ser evidentemente um "vivido" no confronto com a experiência perceptiva. Mesmo em "relativa obscuridade", o papel é "revelado" a ele com toda a sua composicionalidade "natural". A este ato de percebê-lo, exerce-se assim uma cogitatio, que é um ato reflexionante de "ver", "perceber" e "interiorizar". O papel só deixa de ser um "vivido de percepção" e passa a ser um "percebido" no contato experiencial: no modo de vê-lo e tateá-lo. No momento em que não há um "contato" com a coisa material, este "vivido de percepção" não passa a ser outra coisa senão de outra espécie. A explicação é simples: um "vivido" só passa a ser "vivido de consciência" no momento da experiência perceptiva e logo da interiorização deste "vivido" na consciência.

É por isso que Husserl fala muito de "consciência perceptiva" que é quando o "vivido" passa a fazer parte da vivência. Muito embora as coisas apareçam diante de nós com caracterizações distintas, a saber, como coisas reais, fictícias, reconstituídas, imaginadas, etc., a consciência perceptiva ainda assim tem o poder de refletir e discernir qual "campo" pertencem aquelas dadas caracterizações. O "vivido", portanto, passa a ser ora uma coisa explícita, ora uma coisa implícita. A possível "revelação" do "vivido" das coisas em nós é uma característica 
importante da consciência perceptiva. No tocante ao exemplo do papel ao percebê-lo na penumbra, o "vivido de percepção" tornou-se "vivido de consciência" através da experiência perceptiva com os "olhos do espírito". Neste caso, era impossível enxergar o papel com os "olhos físicos" por tamanha obscuridade do ambiente. Husserl, portanto, o tomou por uma espécie de "intuição". É o fato de que no papel estava contido um fundo objetivo cointuído. O que significa dizer que, no intuir, Husserl estar-voltado-para. Este "fundo" seria uma ligeira "impressão" do papel visto com os "olhos do espírito". Esta "intuição" foi originada pela simples e livre mudança de "olhar" para o papel.

A princípio, o papel se encontrava em seu modo originário, pois, neste curso, não lhe aparecia evidentemente. Foi, contudo, com a mudança de "olhar" que o objeto tornou-se explícito para a consciência. A este caso como em outros, os objetos precisam ser percebidos "com atenção", uma vez que haverá outros tantos objetos que o olho captará concomitantemente. Por exemplo: à mesa, podem estar o papel (objeto primário para Husserl) e outros tantos objetos como tintas, pincel, estátuas, cinzeiro, charutos, etc. (objetos, na perspectiva de Husserl, secundários). A percepção pode, eventualmente, "captar" todos os objetos que estão à mesa de uma só vez, mas, seguindo uma orientação natural da consciência, aqueles que se tornarão "explícitos" à primeira vista serão aqueles que tiverem "completado" a síntese perceptiva. De qualquer modo, se Husserl "escava" no ambiente escuro o papel, instantaneamente após experiência perceptiva, o papel é invocado à sua consciência, de modo que este ato pode ser muito mais do que apenas uma reflexão; ele pode acontecer de modo inconsciente, mas jamais de modo involuntário, pois Husserl simplesmente "quis" naquele dado momento perceber o objeto, "detectá-lo".

Este "fluxo de vivido" do papel como demonstrou Husserl jamais pode consistir de apenas puras atualidades. Logo, podemos dizer, com base em Husserl (2006, p. 88), que "não há consciência de coisas apenas na percepção, mas também em recordações, em presentificações semelhantes a recordações e até em livres ficções”. A coisa ou o objeto pode aparecer em nós a partir de "representações obscuras" à primeira vista, mas que se tornam mais "claras" pela interpretação imediata consciente. Ou seja, o "vivido de consciência" pode “aparecer" à consciência vindo de modos de aparição fantasmáticos, como é o caso da alucinação hipnagógica. É quando você "vê" o objeto, mas, na realidade, ele não estava "ali". No exemplo do papel em branco, Husserl no instante em que via o papel, podia lhe "aparecer" fantasmaticamente, uma critatura esquisita como um besouro. A "objetividade" do besouro, por 


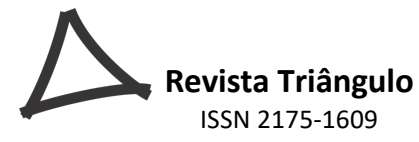

uma experiência perceptiva ilusória, pode tornar-se evidente para Husserl, mesmo no momento em que ele "interiorizava" a existência do papel. Como uma espécie de "lampejo", as coisas dadas como invisíveis podem "aparecer" mesmo em um ambiente material. No caso, é a "força" da consciência de uma memória retrospectiva que faz evocar, em milésimos de segundos, estes "seres" imaginados.

Naturalmente, o eu desperto está em constante estado de percepção instantânea das coisas. Logo, a forma específica do cogito cartesiano também pode estar contido em um fluxo de vividos imaginados ou retrospectivos. A imagem do besouro que Husserl "vê" ilusoriamente está circundada por um processo de organização natural dos vividos: a de que a apreensão originária da vivência da coisa, como o besouro, possivelmente surgiu da passagem imediata do modo de inatualidade para o modo de atualidade. O que isto quer dizer? Que a imagem do besouro não era, à primeira vista, um dado objetivo, material, que Husserl, com sua mera experiência perceptiva, podia percebê-lo. Sendo assim, o besouro "surgiu" à consciência como um modo de aparição intermediário entre a ação perceptiva do papel e a evocação simultânea do besouro. Neste caso, move-se de um ambiente inatual para um ambiente atualizado, partindo-se do modo de doação de sua consciência imagética perceptiva. Se é em geral da essência de todo cogito atual ser consciência de algo, o cogito inatual só passa a ser "atual" através da síntese perceptiva da memória retrospectiva. Porém, o "olhar" para o besouro que "apareceu" fantasmaticamente não deixa de ser um "olhar" imanente, muito embora o aparecimento do fenômeno da coisa em si não tenha originado do mundo material. Aí, falamos de "objetividades simplesmente representáveis" que não necessariamente são apenas os objetos dados de maneira imanente, mas aqueles que são originariamente "representados". Logo, é possível dizer, seguindo Husserl, que a "percepção" se dá também na representação.

O "voltar-se para”, a apreensão do objeto se dá com uma sucinta atenção. Por um dado instante, Husserl deixa de prestar atenção no papel e passa a conter uma parcela de atenção, por mínima que seja, no besouro. Junto à atenção vem o conteúdo reflexionado. É importante salientar que a apreensão originária de qualquer objeto não é de fato essencialmente "originária", da mesma maneira como se viu ou se percebeu. O mesmo podemos dizer da visão tridimensional de um triângulo; nós não vemos todos os lados do triângulo. Se focamos a nossa atenção para um campo visível, nós não "vemos” todas as partes, mas apenas uma só delas. Logo, o objeto que "aparece" a mim pode até conter toda a sua geometria e espacialidade, mas, ao limite de nosso campo visual, só enxergamos aquilo que está mais "visível”, ou seja, apenas 


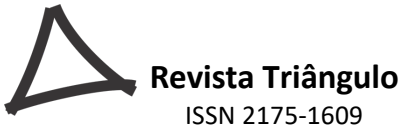

uma parte e não o todo. É justamente por isso que podemos nos “surpreender" com as múltiplas formas da essência do objeto percebido. Estamos, pois, tratando de uma unidade originária imediata e, por ser "imediata", com um único relance, com único brilho de "olhar", nós não somos capazes de "dissecar" o objeto como um todo. A percepção em si é imediata, absoluta, essencial, mas o objeto percebido não pode ser totalmente "captado" em toda sua geometria e espacialidade características.

\section{A CONSCIÊNCIA PERCEPTIVA E A APREENSÃO DO FLUXO DE VIVIDO}

Husserl (2006, p. 94, grifos do autor) diz: "a consciência individual está entrelaçada ao mundo natural de uma dupla maneira: ela é consciência de algum homem ou animal e é, ao menos num grande número de suas particularizações, consciência deste mundo". Seguindo o princípio do cogito cartesiano: "Penso, logo existo", o ato de pensar torna o ser, homem ou animal, existente e é, pois, dentro desta "existência consciente" que passamos a ter "consciência" do mundo. O animal, assim como o homem pensa, exerce uma experiência perceptiva, tem memória retrospectiva, etc., podemos dizer até que o animal "tem" uma certa consciência de sua subjetividade e, por fim, ele chega a "refletir". No entanto, é natural ao homem criar, mudar, contornar, voltar, reinserir, problematizar, equacionar, dizer, temporalizar, discernir, etc. Pelo visto, a experiência originária perceptiva do homem não é a mesma a do animal. O animal vive para sobreviver e ainda ele não é capaz de "categorizar" os modos de aparição do vivido. As suas vivências, pois, já estão como que “determinadas”. Já o homem tem um aparelho perceptivo muito mais complexo; a partir das vivências, ele "interioriza" e "categoriza" os vividos, torna-os, pois, "conscientes", do "vivido de percepção" chega-se ao "vivido de consciência". Vamos a mais um exemplo de Husserl (2006):

Comecemos por um exemplo. Vendo sempre esta mesa, dando uma volta em torno dela, modificando como sempre minha posição no espaço, tendo continuamente a consciência de que é uma única e mesma mesa que está corporalmente aqui, e dela mesma que permanece em si inteiramente inalterada. A percepção da mesa, porém, é uma percepção que se altera constantemente, é uma continuidade de percepções cambiantes. Fecho os olhos. Meus demais sentidos estão fora de relação com a mesa. Não tenho agora nenhuma percepção dela. Abro os olhos, e volto a ter a percepção. A percepção? Sejamos mais precisos. Ao retornar, ela não é em nenhuma circunstância a mesma. Apenas a mesa é a mesma, tenho consciência dela como idêntica na consciência sintética que vincula a nova percepção à recordação. A coisa percebida pode existir sem que seja percebida, sem que nem mesmo se tenha potencialmente consciência dela e pode existir sem se alterar (HUSSERL, 2006, p. 97-98). 


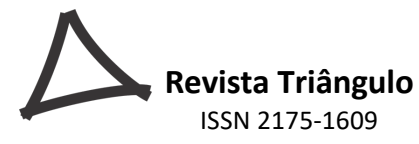

Com esta citação, podemos estar cientes de que a percepção nunca será a mesma, assim como o nosso pensamento em torno de uma coisa nunca será o mesmo. Vivemos a todo instante, enquanto seres viventes, uma passagem instantânea entre atualidade e inatualidade e vice-versa. As coisas ou os objetos estão o tempo todo desatualizados e precisamos, então, torná-los "atuais". Ou, inversamente, os objetos estão sendo atualizados e precisamos "desocultá-los", reinseri-los na passagem anímica da vida. Ou seja, torná-los "vivos" novamente. Neste interim, a percepção jamais será a mesma. Se eu tenho diante de mim um objeto como uma mesa e ao fechar os olhos e abri-los novamente posso "perceber" que é a mesma mesa em sua fisicalidade, contudo, a apreensão imanente não é exatamente esta. Quando é inferida uma "nova percepção", nós apelamos para a recordação. O que isto quer dizer? Que no momento de "ver" a mesa após o fechar e abrir os olhos, a apreensão da imagem "nítida" na consciência reinsere um novo modo de aparição da mesma mesa partindo de uma nova síntese reformulada pela memória retrospectiva. A apreensão originária no contato inicial com a mesa é uma, a apreensão da mesa após abrir os olhos é outra. Como o próprio Husserl (2006) diz, no ato de perceber a mesa, há uma “continuidade de percepções cambiantes". Através de nossa experiência perceptiva, a mesa "altera" o seu modo de doação constantemente.

Seguindo este raciocínio, nós percebemos a coisa justamente porque ela "se perfila" a todo instante. Nós não "vemos" esta "alteração" a olho nu, mas a mesa "se perfila", ou seja, há, pois, uma sucinta e quase desapercebida "mudança" na cor ou em sua forma. Hussserl (2006, p. 98) esclarece: “a cor da coisa vista não é, por princípio, momento real da consciência de cor, ela aparece, mas, enquanto aparece, a aparência pode e tem, na experiência que a exibe, continuamente de se alterar". Partindo deste sentido, todo objeto espacial "decide se alterar" animicamente, é como se ele "se movimentasse", mas não "movimento" no sentido de "moverse de um lugar para outro", mas "movimento" no sentido de mudança. Logo, podemos "ver" uma certa cor em uma mesa, mas, na realidade, ela tem outro tom. O que nos "surpreende" é o "evidente", o que é "concreto", e só podemos enxergar o que o nosso olho é capaz de "ver". Portanto, há um certo limite em nosso campo visual mesmo em pessoas que estão desprovidas de alguma deficiência visual. Se caso fôssemos "ver" esta mesma mesa com um telescópio ou uma lupa, possivelmente perceberíamos que ela possui outras nuâncias e outras tonalidades que a olho nu não podemos percebê-las. 


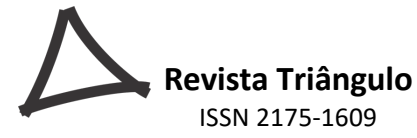

E aí vem a crítica de Husserl ao psicologismo e, mais detidamente, ao cognitivismo. Ele nos diz: "O que induz ao erro é pensar que a transcendência da coisa é a transcendência de uma imagem ou de um signo" (HUSSERL, 2006, p. 102). De uma certa forma, Husserl "combate" ardorosamente as ciências do "espírito" que veem o "conteúdo representativo" como uma certa "transcendência". "Transcendência" porque, dentro de um certo limite, a nossa consciência tem o poder de "representar" o objeto percebido na forma de uma imagem. E Husserl contraria esta posição e vê que aí não há nenhum tipo de "transcendência", uma vez que a "consciência perceptiva" é formada por uma "percepção" do objeto em carne e osso. Segundo ele, não há como, pela percepção, "presentificar" uma coisa que não está presente. A percepção só é "percepção" em carne e osso, viva, evidente, transparente e imediata. "Não se deve introduzir secretamente na percepção uma consciência de signo ou de imagem" (HUSSERL, 2006, p. 102). Cabe frisar que Husserl não está se referindo à percepção na imaginação. Ao contrário, para ele, não existe este tipo de "percepção". A percepção em si, genuína, se dá no contato imediato com o "corpo" ou a "materialidade" do objeto, ou seja, em seus múltiplos modos de aparição.

Angela Ales Bello, profunda estudiosa de Husserl e membro-presidente de instituições que estudam fenomenologia em Roma, escreve em seu livro $O$ sentido das coisas: por um realismo fenomenológico o seguinte: "a consciência não é um lugar ou uma caixa que contém alguma coisa; ela é constituída de experiências a serem vividas conscientemente, eis porque se lhes dá o nome de vivências (Erlebnisse). De fato, Edith Stein define a consciência como uma luz interior que acompanha as Erlebnisse" (BELLO, 2019, p. 30-31). Diante destas indagações, não há como encontrar a consciência em um "receptáculo"; não dá, pois, para "dissecar" o "conteúdo" da consciência. Falamos de "conteúdo psíquico", mas não necessariamente no sentido de um "local físico" que contenha a consciência. Logo, a consciência nós não podemos vê-la, tateá-la, percebê-la (no sentido literal da palavra). Porém, podemos até certo ponto "percebê-la" através da revelação ou do aparecimento de experiências vividas, ou seja, partindo-se do "compartilhamento" de vivências. Segundo Bello (2019), Edith Stein, que também é uma profunda estudiosa de Husserl, vê estas vivências como uma específica "luz interior". É como dizemos anteriormente, para cada vivido, há uma "luz" própria imanente que é evidentemente "dissecada" através de experiências perceptivas.

O vivido só vem à luz através do ato de percepção. Muito embora as coisas, até as inanimadas, possuam uma "luz" interior, mas esta "luz" é "diagnosticada" como uma espécie 


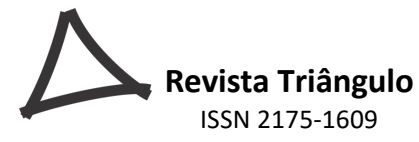

de "linguagem", mesmo sem a interferência da ação perceptiva. A saber, a "linguagem" não pertence apenas ao que é do humano, a "linguagem" está no mundo, as coisas em si "possuem" uma linguagem natural. Aonde existe vida, coexiste linguagem. Assim que o mundo surgiu, a "linguagem" o constituiu animicamente. Partindo deste ponto, a "luz interior" não é tão somente uma "luz" que é apreendida por uma experiência perceptiva; a "luz interior" das coisas está intrinsecamente relacionada à existência de linguagem. Seres animados ou não, "possuem" uma "linguagem própria" revelada em sua estrutura, espacialidade e tonalidade. Muito embora esta "luz" só se torna evidentemente e essencialmente "interior" quando se passa pelo "fio condutor" do ato reflexionante. O mesmo se pode dizer do "vivido". O "vivido" só "adere" uma certa vivacidade na apreensão originária da coisa. Neste sentido, a consciência faz todo o trabalho de “captação" do "fluxo do vivido", não encontrando "limites" para a sua devida apreensão.

Angela Bello (2019) diz: "para Husserl, a consciência não é um conjunto de funções independentes do objeto os quais estas funções se aplicam, mas a consciência é a própria estratificação das operações constitutivas, ativas e passivas, que formam o objeto (BELLO, 2019, p. 46, grifo nosso). Neste sentido, a consciência perceptiva humana "estratifica" o objeto; o que isto quer dizer? É como se, no momento da percepção, a consciência fizesse um checkup ou um "diagnóstico geral" do objeto. Este objeto só passa a ser evidentemente percebido quando há este processo de "estratificação". Ou seja, a consciência "extrai", "apreende" ou "desoculta" o que à primeira vista não estava "visível". No momento da devida "apreensão", o eu é "sinalizado" pela consciência sobre o modo de aparição e deslumbramento do objeto. Muito embora, segundo Bello (2019), a subjetividade é muito mais ampla que o próprio eu. Mas, por que isto acontece? Justamente porque a "subjetividade" está para o "fundo" da experiência, enquanto que o "eu" "se apresenta" apenas como uma "superfície" desta experiência. Há na "subjetividade" toda a "construção" ontológica do sujeito sendo que, para este sujeito, é "assinalado" ou "alertado" sobre uma possível "mudança" ou "ruptura" do componente subjetivo. Neste sentido, a "subjetividade" "está" no "eu", porém, muitas das mudanças que ocorrem nesta "relação", o sujeito não é "avisado". Só, evidentemente, mais tarde, em um momento propício, o "eu" interioriza aquela dada mudança.

Ernildo Stein (2004), também profundo estudioso de Husserl, no livro Mundo vivido tece o seguinte comentário: "não há experiência se não houver uma experiência, isto é, se não houver algo que nós já sempre experimentamos, mas que não podemos descrever como experiência porque nos escapa. É o chão originário, o lugar onde algo caiu, onde algo se 


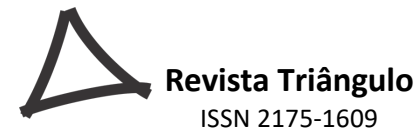

estabeleceu, mas que não se recupera" (STEIN, 2004, p. 31, grifo do autor). Se estamos lidando com o sentido de "experiência" é justamente por ela ser "imediata". Logo, "experiência" se vive e ponto final. Não há como "recuperar" imaginativamente um objeto que caiu no chão, ele caiu e isto é evidente. É o mesmo que dizer que "o leite derramou”; não há, pois, como "voltar" atrás e "modificar" o ocorrido. Aconteceu, aconteceu! É neste sentido que Stein (2004) esclarece sobre o "uso" da experiência. Há, porém, uma possibilidade de recuperar as experiências, mas elas jamais serão as mesmas, nunca serão dadas como objetivas.

Quando acontece uma experiência com um dado objeto, haverá, pois, outras experiências com o mesmo objeto, até certo ponto "semelhantes", mas nunca serão as mesmas em carne e osso. Ou seja, o "fluxo de vivido" se altera incessantemente. Temos a ilusão, porém, de "estar executando" a mesma experiência sucessivas vezes quando o objeto em si continua "estático", mas uma mudança de olhar, uma reposição do corpo, altera significativamente a apreensão da experiência. São, portanto, horizontes de uma experiência que devem ser "presumidos", logo, não podemos dizer que, para tudo aquilo que seja experienciado aquilo seja verdadeiro. Lidamos muito mais com "falhas" do que com "acertos" na experiência. Segundo Stein (2004, p. 37), "mundo é a matéria de significabilidade que desde sempre foi-se acumulando". Já a "experiência" é o espírito de significabilidade que vai se alterando conforme o fluxo vivido da consciência. O conceito de "mundo da vida" husserliano quer dizer o "vivenciamento" da consciência e este conceito serve tanto para o homem quanto para tudo aquilo que existe vida.

De acordo com Cerbone (2014), "assim como objetos são constituídos dentro do fluxo da experiência, o mesmo se dá com o ego. À medida que a experiência continua, movendo-se em direções particulares, tendo seus conteúdos mudando de diversos modos, o ego é construído precisamente como o sujeito dessa experiência" (CERBONE, 2014, p. 57, grifo do autor). Seguindo esta perspectiva, a "consciência perceptiva" só é dada como "perceptiva" porque há o "vivenciamento" do ego, ou seja, neste processo de "vivenciar", o ego "se abre" para "receber" o desvelamento do objeto após a percepção. Aí vem o conceito de "conteúdo intencional" de Husserl que nada mais é do que a "vontade" ou a "predisposição" do eu em experienciar e rexperienciar aquele dado objeto. Se eu estou, em um dado momento, me "referindo" ao objeto, eu estou, de uma certa forma, percebendo-o intencionalmente. Neste sentido, podemos falar que o "psíquico" é um fenômeno e não uma coisa. Por isso, parte daí a crítica de Husserl às ciências do "espírito" que veem a consciência como uma coisa, como um 
objeto verificável. Em contrapartida, para Husserl, o fenômeno é a consciência enquanto fluxo temporal de vivências.

O estudo da Fenomenologia é justamente o estudo daquilo que aparece à consciência, daquilo que se manifesta, que se abre, que se revela. Ou seja, é "deixar" ou "fazer ver" por si mesmo aquilo que se mostra em carne e osso. Nesta perspectiva, o homem é apresentado ao mundo como potência de vida, como possibilidade de "interação" com as coisas deste mundo e com a possilidade de "executar" experiências. A fenomenologia vê a consciência e o mundo como "correlatos", como "realidades" que se interconectam, que se justapõem. E o homem, por ser "potência de vida", é rico em vivências, em experiências, é um "organismo" vivo rico em “constituintes psicológicos". Logo, a consciência, para Husserl, seria o dado mais imediato da existência. A "imediatez" do sentido da existência é tão absoluta na consciência que se equipara à velocidade infinitesimal do ato de pensar. Ou seja, sem pensar que pensamos, já estamos pensando. A matéria do pensamento "torna-se" "espírito" com a existência subita da consciência. Nos diferenciamos dos animais e de outros seres semelhantes porque contemos a consciência da espiritualidade, a manifestação do divino em nós. A “observação interior” seria um "movimento" constante à espiritualidade.

E, muitas das vezes, entendemos este "movimento à espiritualidade" como uma "retrospecção", como uma evocação mnemônica, como se a "existência" do divino estivesse contida em nossa memória individual, no "movimento" de recuperar, de retroceder, de revivenciar. Afinal, para termos consciência da existência de Deus é fundamental esta evocação diária da figura de Deus como ser supremo, perfeito, infinito, onipresente, atemporal, etc. Como para Kant que diz que Deus é necessário até porque a noção de moral é de suma importância. Para finalizar, segundo Merleau-Ponty (2017, p. 23), “minha relação com as ideias é, portanto, idêntica à minha relação com o mundo percebido". Merleau-Ponty foi um importante continuador dos pensamentos de Husserl, ele observou a importância da consciência perceptiva nos traços do/sobre o mundo. Para Merleau-Ponty, toda ideia é uma "luz", um traço constituinte da representação de algo. A percepção para este filósofo se assemelha a de Husserl, no entanto, Merleau-Ponty insere, ao fenômeno da percepção, a lógica do corpo, essência fundamental para a "captação" das coisas do mundo circundante. 


\section{CONSIDERAÇÕES FINAIS}

À guisa de conclusão, podemos inferir que a Fenomenologia é um estudo muito específico que, de uma certa maneira, não admite a "entrada" de correntes puramente "subjetivistas" ou "cognitivistas". A figura de Husserl é de extrema importância no sentido de que ele, a partir de seus estudos com seu professor Brentano, pôde "criar" uma ciência cujo foco central é a experiência viva do cogito. Neste sentido, Descartes não foi tão longe quanto Husserl foi porque o primeiro estava preocupado apenas com a "explicitação" do cogito, enquanto que o segundo preocupou-se com a "descrição" detalhada do fluxo de vivência do cogito.

O que resta-nos é a lição de que nós, enquanto seres naturalmente viventes, devemos "tornar" mais concreto a nossa relação com as coisas que nos circundam. De ainda tornamos mais "conscientes" sobre o momento de percepção das coisas do mundo: em que nós tocamos e com que finalidade? Para, a partir daí, conseguirmos ter uma "consciência" mais fidedigna (uma maior sensibilidade) com o que estamos vendo, tocando, percebendo e, por fim, vivenciando. O fim último de tudo é a percepção e ela há de existir enquanto houver vida perceptiva.

\section{REFERÊNCIAS}

BELLO, A. A. O sentido das coisas: por um realismo fenomenológico. Tradução de José J. Queiroz. São Paulo: Paulus, 2019.

CERBONE, D. R. Fenomenologia. Tradução de Caesar Souza. Petrópolis: Vozes, 2014.

HUSSERL, E. Ideias para uma fenomenologia pura e para uma filosofia fenomenológica. Tradução de Márcio Suzuki. Aparecida: Ideias \& Letras, 2006.

MERLEAU-PONTY, M. A união da alma e do corpo em Malebranche, Biran e Bergson. Tradução de Sílvio Rosa Filho e Thiago Martins. Belo Horizonte: Autêntica, 2017.

MERLEAU-PONTY, M. Fenomenologia da percepção. Tradução de Carlos Alberto Ribeiro de Moura. São Paulo: Martins Fontes, 2018.

STEIN, E. Mundo vivido: das vicissitudes e dos usos de um conceito da fenomenologia. Porto Alegre: EDIPUCRS, 2004. 